\title{
Review of: "Complete mitochondrial genome sequencing of Oxycarenus laetus (Hemiptera: Lygaeidae) from two geographically distinct regions of India"
}

\author{
Kar Hoe Loh $^{1}$ \\ 1 Universiti Malaya
}

Potential competing interests: The author(s) declared that no potential competing interests exist.

The authors report on the complete mitochondrial genome sequencing of Oxycarenus laetus from two geographically distinct regions of India, using MiSeq Illumina sequencer to generate paired-end reads of length $75 \mathrm{bp}$. The paper in general carefully written. The Raw data generated were submitted to NCBI's SRA Archives (PRJNA520830). Finally, the complete genome was 15,672 bp identified, it consisting of 13 PCGs, 2 rRNA, 23 tRNA genes, and a 962 bp control region. This was an article whose findings are important to those with closely related hemipteran super-families research interests. 